University of Nebraska - Lincoln

DigitalCommons@University of Nebraska - Lincoln

U.S. Environmental Protection Agency Papers

U.S. Environmental Protection Agency

2004

Sustainable Futures: Encouraging Risk Screening of Industrial

Chemicals at the R\&D Stage

Maggie Wilson

U.S. EPA

Follow this and additional works at: https://digitalcommons.unl.edu/usepapapers

Wilson, Maggie, "Sustainable Futures: Encouraging Risk Screening of Industrial Chemicals at the R\&D Stage" (2004). U.S. Environmental Protection Agency Papers. 186.

https://digitalcommons.unl.edu/usepapapers/186

This Article is brought to you for free and open access by the U.S. Environmental Protection Agency at DigitalCommons@University of Nebraska - Lincoln. It has been accepted for inclusion in U.S. Environmental Protection Agency Papers by an authorized administrator of DigitalCommons@University of Nebraska - Lincoln. 


\section{Sustainable Futures: Encouraging Risk Screening of Industrial Chemicals at the R\&D Stage}

U.S. EPA's Office of Pollution Prevention and Toxics (OPPT) has developed computerized methods for predicting the risk of industrial chemical toxicity based on an analysis of chemical structure. Under the Sustainable Futures Pilot Project, industry is beginning to realize tangible business and pollution prevention benefits from the use of these methods.

This article discusses the development of the Sustainable Futures program and highlights some of the benefits to business, regulators, and the environment.

\section{Background: Regulation of Chemicals}

Three general groups of chemicals are regulated in the United States: pesticides, pharmaceuticals (drugs), and industrial chemicals. The inherent nature of these chemicals varies, as do the purposes for which they are developed and used. This has resulted in different approaches to the regulation of these chemicals.
Pesticides and

Pharmaceuticals

Pesticides are designed to be toxic to specific target organisms in order to control or eliminate organisms that create problems for society (such as rats, roaches, termites, weedy plants, molds, and other destructive microorganisms).

Pharmaceuticals are also designed to have specific biological activities; they are used to control or eliminate infectious agents and regulate physiological functions.

Because pesticides and pharmaceuticals must possess specific biological activity in order to function in the desired manner, regulators must be certain that their use will not result in any undesirable or unintended harm. In order to ensure public safety, the U.S. Congress passed the Federal Insecticide, Fungicide and Rodenticide Act of 1972 (FIFRA) to control pesticides. An earlier 
Congress had already adopted the Food, Drug and Cosmetic Act of 1938 (FDCA) to control pharmaceuticals.

These laws give regulators of these groups of chemicals broad and specific authorities. Both FIFRA and FDCA state that before a chemical can enter commerce, regulators must receive specific experimental laboratory data that clearly demonstrate that the chemical will behave in the prescribed manner and not cause unin-

Unlike pesticides and pharmaceuticals, industrial chemicals are not designed to have specific biological activity. tended harm to humans or the environment. A wide range of specific tests, costing many millions of dollars and multiple years to complete, are often required.

EPA's Office of Pesticide Programs regulates and controls pesticides, while the U.S. Food and Drug Administration (FDA) regulates and controls pharmaceuticals.

\section{Industrial Chemicals}

Chemicals that are not pharmaceuticals or pesticides generally are considered "industrial chemicals" (except for explosives and radiological materials). Industrial chemicals serve an incredibly broad range of uses.

Unlike pesticides and pharmaceuticals, industrial chemicals are not designed to have specific biological activity. As a result, no targeted testing is required before industrial chemicals go into commerce.

\section{Pesticides and Pharmaceuticals Are Data- Rich; Industrial Chemicals Are Data-Poor}

Because of these different regulatory schemes, we have different levels of knowledge about the three groups of regulated chemicals. In general, pesticides and pharmaceuticals are rich in pub- licly available data, while industrial chemicals are data-poor.

\section{Industrial Chemicals Can Be Found Nearly Everywhere}

We all come into contact with industrial chemicals every day. Industrial chemicals are used in a very broad array of goods, products, and services, including (among many others):

- laundry detergents and household cleaners;

- fabrics and carpets;

- paper finishes and inks;

- paints and dyes;

- food containers;

- personal care products, like hair- and toothbrushes;

- children's toys;

- automobile components; and

- computer components.

The fresh scent of your fabric softener, the blue dye in your jeans, that "new car smell"-all are the result of industrial chemicals.

In addition, many solid materials, such as particleboard in your furniture or your home, have been produced with industrial chemicals and may still have these chemicals as critical components.

\section{The Public Becomes Aware of Industrial Chemicals}

Until the mid-1970s, there were no federal laws controlling industrial chemicals. Regulation of these chemicals became a priority in the United States after the report of some major, manmade environmental disasters.

One such incident was in the neighborhood of Love Canal in New York State, where a school and many homes were built on top of an old industrial dumpsite containing toxic chemicals, including polychlorinated biphenyls (PCBs). An- 
other incident involved the discovery of extensive dioxin contamination of the roads and soils in Times Beach, Missouri.

Because of widely reported incidents such as these, the general public began to recognize that exposure to some industrial chemicals could result in risks to human health and the environment.

\section{Toxic Substances Control Act: Regulation of Industrial Chemicals}

In response to these increasing concerns, Congress passed the Toxic Substances Control Act (TSCA) in 1976. This law authorized EPA to control the manufacture, import, use, distribution, and disposal of industrial chemicals. TSCA is implemented by EPA's Office of Pollution Prevention and Toxics.

TSCA does not require testing of new chemicals, but does require that OPPT review new chemical submissions within 90 days.

\section{TSCA Requirements Differ from Those of FDCA and FIFRA}

TSCA is fundamentally different from FIFRA and FDCA because, as previously discussed, the nature of the chemicals regulated by each law is fundamentally different.

Pharmaceuticals and pesticides must be registered with the regulating authority before they can enter commerce. The registration processes require that results from specific rigorous human health toxicity tests be submitted so that the authorities can comprehensively evaluate any potential risks from exposure to the chemical.

Testing may be conducted for carcinogenicity, reproductive and developmental toxicity, chronic toxicity, neurotoxicity, mutagenicity, organ toxicity, eye irritation, and skin and/or lung sensitization, among other endpoints. Environmental testing is also required. This can include testing on environmental fate and persistence, and acute and chronic toxicity to fish, birds, and other terrestrial species.

These testing requirements mean that a company must invest millions of dollars in a chemical they wish to bring to market. In addition, EPA and FDA typically take years to evaluate test data submitted with a chemical.

The burden of proof for safety rests squarely with the company wishing to manufacture or import pesticides or pharmaceuticals. The company must demonstrate to the regulator that the chemical is safe for the intended purpose. In addition, the chemical must carry an approved label that clearly states the specifics of use (including dose or application rates) and prohibitions on use.

The burden of proof for safety is very different for industrial chemicals. Under TSCA,
Pharmaceuticals and pesticides must be registered with the regulating authority before they can enter commerce. there is no requirement for chemical companies to conduct testing of any kind before commencing manufacture for commercial purposes. The regulatory structure for industrial chemicals under TSCA differs markedly from that of drugs and pesticides.

\section{"Existing" versus "New" Chemicals:} Chemicals Are New by Virtue of the Law, Not Science

Shortly after TSCA was passed in 1976, EPA issued a Federal Register notice asking manufacturers and importers of industrial chemicals to send notice to the Agency (a postcard was adequate) listing the names of chemicals they manufactured or imported that were currently in commerce in the United States.

This list of chemicals became the TSCA Inventory of Existing Commercial Chemical Substances. In effect, the TSCA Inventory "grandfa- 
thered" chemicals that were already in commerce at the time the Inventory was created. This grandfathering ended when the original TSCA Inventory was completed in 1979. The original Inventory contained approximately 60,000 chemicals.

This grandfathering of chemicals in commerce when TSCA was enacted would turn out to be a major factor contributing to our lack of toxicity and risk data on chemicals in commerce, because existing chemicals are treated differently from new chemicals under TSCA.

\section{EPA Must "Show Cause" to Request Data on Existing Chemicals}

\section{Under TSCA, manufacturers and im- porters are free to use "existing" chemicals (that is, those included in the Inventory) for any purpose.}

Under TSCA, manufacturers and importers are free to use "existing" chemicals (that is, those included in the Inventory) for any purpose. No registration or labeling is needed.

Testing of these existing chemicals is not a condition of manufacture or use. Under TSCA, EPA can require testing of existing chemicals if the Agency can "show cause" why testing is necessary, and go through a lengthy notice-and-comment rulemaking process. The burden of proof regarding the need for testing is on EPA and not on the manufacturers/importers/ users of these existing chemicals.

\section{New Chemical Submissions Often Have No Data}

TSCA requires that anyone wishing to commercialize a chemical not already on the Inventory (i.e., a "new" chemical) must submit a Premanufacture Notice (PMN) to EPA OPPT.

As stated on the OPPT New Chemicals Program Web site, http://www.epa.gov/oppt/newchems (as accessed February 19, 2004), PMN sub- missions must include "all available data on chemical identity, production volume, byproducts, use, environmental release, disposal practices, and human exposure." In addition, the PMN should include "all existing health and environmental data in the possession of the submitter, parent company, or affiliates, and a description of any existing data known to or reasonably ascertainable by the submitter."

The reality, however, is that most often human health and environmental toxicity data are not readily available to the submitter, and are not submitted with the PMN. Submitters are not required to do any additional specific toxicity testing on chemical substances.

OPPT has noticed that typically only a small fraction of PMNs contain human health or aquatic toxicity data, and endpoints vary. OPPT staff scientists say that about 15 percent have at least some mammalian toxicity data, and only 4 percent have repeat dose study data (28- or 90day); less than 5 percent contain aquatic toxicity data, and about 10 percent have data on physical chemical properties and/or environmental fate (J. V. Nabholz, R. Jones-EPA OPPT, April 15, 2004, personal communication). In addition, the data submitted quite often are claimed as confidential and cannot be made publicly available.

The result is that most PMNs, even those that do contain data, do not contain test data adequate to fully characterize the risks that their chemicals may pose.

\section{EPA Must Review PMNs, Which Often Lack Data, in 90 Days}

EPA OPPT must complete their assessment of PMNs and describe any necessary regulatory actions required to control risk within 90 days, although the 90-day clock can be stopped if necessary. OPPT typically regulates or controls about 10 percent of PMNs submitted. One type of regulatory action is "prescribed use and exposure" controls. 
In the early years of TSCA, few PMNs were submitted to EPA. The number of PMN submissions has steadily increased, however, and EPA currently receives 1,500 to 2,000 per year. In order to deal with the increasing volume, OPPT had to develop a process to essentially "triage" PMNs. Chemicals known to be low-toxicityand, therefore, low-risk-could be given less scrutiny, allowing EPA scientists to focus on those chemicals that may present higher risk.

OPPT developed exemption rules for those chemicals that the Agency believes will not pose a risk. Examples of current exemptions are those for:

- certain polymers;

- low-volume and low-exposure chemicals; and

- research and development applications.

\section{OPPT's Approach to Evaluating Chemicals in the Absence of Data: Necessity Is the Mother of Invention}

Faced with the challenge of rapidly assessing many chemicals that most often have no toxicity data, the Agency developed a stepwise evaluation process. The steps in this process include nearest analogue analysis; the chemical categories approach; and computerized predictive methods known as SARs and QSARs. Each of these is described below.

\section{Nearest Analogue Analysis}

Since no data are available for most PMN chemicals, OPPT uses measured data on structurally related compounds (analogues) to estimate the toxicity of the PMN chemical.

Identification of close analogues requires the judgment of a highly qualified chemist. OPPT is fortunate to have experienced, exceptionally wellqualified chemists on staff who spend most of their time on work related to PMN chemical review.

OPPT staff search previous PMN cases to determine if they have seen this chemical before.
OPPT has databases of information on chemical PMNs over the past 20-plus years, as well as the outcome of every chemical review.

While nearest analogue analysis is effective, it is also time-consuming and labor-intensive. As the volume of PMN submissions increased, the Agency had to develop additional methods for evaluating PMN chemicals in order to remain within the 90-day time frame allowed by TSCA.

\section{Chemical Categories Approach}

By the late 1980s, OPPT had enough experience with certain types of chemicals to be able to group them into prescribed categories that share common characteristics. With this accumulated expe-
Within a prescribed category, the toxicity concerns and test recommendations vary little from chemical to chemical. rience, OPPT created

the Chemical Cate-

gories Report, available

online at http://www.epa.gov/oppt/newchems/ chemcat.htm. This report has information on more than 50 classes of chemicals.

Within a prescribed category, the toxicity concerns and test recommendations vary little from chemical to chemical. Thus, if a new PMN chemical is identified as being a member of an established category, the potential health or environmental concerns (or absence of concerns) associated with that category can be attributed to the chemical.

While this category approach does not include all types of substances, new categories are added when justified by data and professional judgment. In addition, this category-based approach has allowed OPPT to share some of its accumulated expertise with the chemical industry and the general public, even though the underlying data that OPPT used to develop the categories may be confidential. 


\section{SARs and QSARs: Scientifically Sound Computational Toxicology Methods}

The old adage, "If it walks like a duck, and quacks like a duck, it must be a duck" describes the basis for Structure Activity Relationships (SARs) and Quantitative Structure Activity Relationships (QSARs).

Rather than using a tested analogue to predict the potential toxicity of an untested chemical, SAR and QSAR analyses are based on observations that the properties or toxic activities of a chemical can be associated with a particular descriptor of the compound, such as molecular shape or water solubility.

\section{OPPT has developed a wide range of SARS/QSARs for many endpoints, including both human health and environmental toxicity.}

\begin{abstract}
Using validated measured data, a regression equation can sometimes be developed that mathematically describes the relationship between the chemical descriptor and the property or activity. That regression
\end{abstract} equation can then be used to predict the properties or toxicity of an untested chemical.

OPPT has developed a wide range of SARs/QSARs for many endpoints, including both human health and environmental toxicity. One of the more widely known OPPT SAR models is ECOSAR (Ecological Structure Activity Relationship), which currently contains the computerized SARs equations for more than 60 chemical classes, as described in the model's "Help" functions.

Additional SARs are being programmed into ECOSAR as resources allow. OPPT is also exploring the development of human health QSARs that can incorporate the wealth of data received by the New Chemicals Program.

Development of computerized models constructed using confidential data received by the
Agency is another way of providing access to EPA's expertise, as well as permitting indirect use of confidential data, while still ensuring the protection of companies' proprietary interests.

In the long run, these computerized models can make the best use of everyone's dwindling resources. They can also help avoid unnecessary (and increasingly unpopular) animal testing.

\section{Outreach Programs Teaching Industry To Use EPA's Screening Models: Legacy of the Pollution Prevention Act}

The Pollution Prevention Act (PPA) of 1990 describes basic concepts that, if followed, will greatly reduce environmental pollution. The PPA creates a hierarchy of approaches for dealing with pollution. The Act provides that pollution should be prevented or reduced at the source if possible. If this cannot be achieved, waste should be recycled. Disposal or environmental release should occur only as a last resort. Following passage of the Act, EPA looked for ways to incorporate these concepts into Agency programs.

OPPT staff, working within the New Chemicals Program, were aware of a situation commonly encountered when PMN chemicals had to be regulated. Staff observed that PMN submitters often could have been alerted to potential toxicity and risk concerns if, during development of the regulated chemical, the submitter had used the screening methods that OPPT developed to screen PMN chemicals.

If a company that is developing a PMN submission realizes that manufacture of its chemical would result in, for instance, worker inhalation concerns, the submitter could request certain worker handling practices in order to eliminate exposure-and, therefore, risk to workers.

Similarly, if the submitter has five alternative chemicals which, based on availability and performance, could be used for the desired application, he or she can screen all five candidates and 
then select for the PMN the one that has the most environmentally preferable properties (for example, the chemical that is least toxic to fish).

In these general examples, the PMN submitters would be able to avoid delays resulting from having the Agency identify toxicity, get back to the submitter, and require the submitter to add the controls required to mitigate risk.

The Agency had essentially been telling industry, "Send in your chemical and we will tell you if it will be allowed." By the time that OPPT reviews a PMN, most of the pollution prevention opportunities have already been lost. This situation does not encourage the innovation needed to work toward preventing pollution.

\section{Making EPA Screening Models Available to Industry Can Benefit Everyone Involved}

Giving OPPT risk-screening methods to the chemical industry for use at the research and development stage seemed like an idea that could be beneficial to everyone. These tools can help industry identify and take advantage of pollution prevention opportunities even before a chemical is synthesized. For this reason, OPPT wanted to make these methods publicly available to encourage risk screening as early as possible in the chemical development process.

Exhibit 1 illustrates why early prescreening can be so beneficial to industry. As this graphic shows, companies often do not perform toxicity

Exhibit 1. Chemical R\&D Process-Status Quo

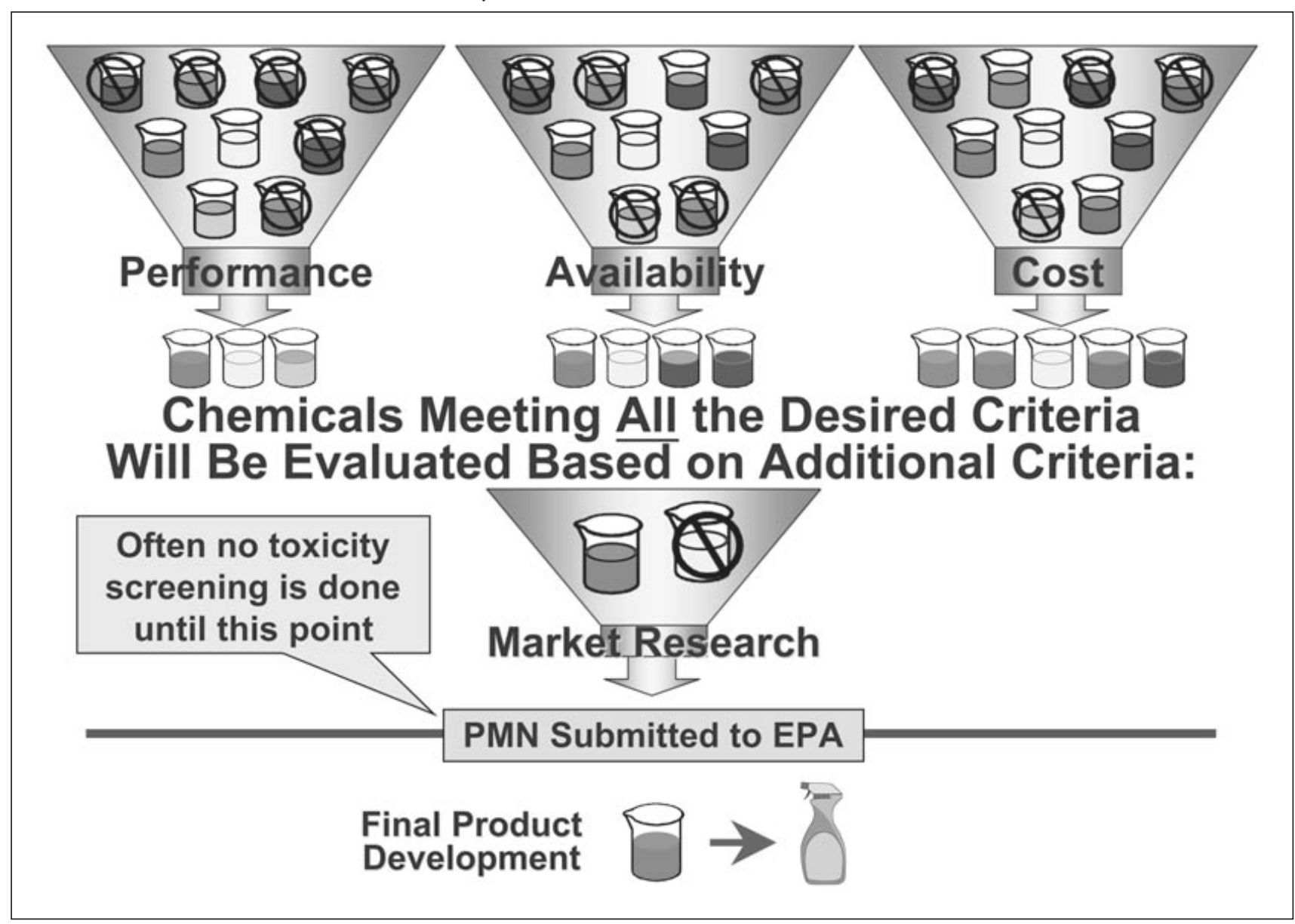


screening until the point at which the PMN is submitted to EPA. If the company discovers at this stage that its chemical poses toxicity concerns, it will already have spent considerable time and resources on the development process-and may have missed opportunities to consider alternatives or mitigate the toxicity threat.

Initial reactions to EPA's outreach efforts were predictable. Within the Agency, some expressed the belief that it was wrong to give industry OPPT methods. After all, we would be using those same methods to review industry chemicals. To some, this was seen as giving the fox the key to the henhouse!

\section{Within the Agency, some expressed the belief that it was wrong to give industry OPPT methods.}

\section{Can the Technology Be Successfully Transferred?}

OPPT wanted to conduct a small pilot project to learn whether the risk-screening methods used during the review of new chemicals could be successfully transferred to the chemical industry.

\section{Kodak Pilot Project}

EPA and Eastman Kodak reached an agreement to form a partnership for a pilot project. After giving Kodak the screening models, OPPT met with Kodak technical staff several times to help them understand the model limitations, practice using the models, and interpret the model results.

Kodak and OPPT collaborated on a series of test cases running the models. Kodak gave OPPT a set of chemicals, and then both Kodak and OPPT evaluated the chemicals independently using OPPT screening models.

When Kodak and OPPT met to compare screening results, everyone was gratified to see that the model results from the separate evaluations were almost identical. Kodak continues to use these screening methods after incorporating them into their chemical product development process.

\section{The P2 Framework Is Born}

Based on the highly successful Kodak pilot project, OPPT combined their chemical toxicity and risk screening models into the Pollution Prevention (P2) Framework. OPPT then developed an aggressive outreach program offering seminars and workshops on the use, interpretation, and limitations of the P2 Framework models.

I was fortunate to be offered the task of developing the documentation for this outreach effort. Working with EPA subject matter experts, I put together the P2 Framework Manual, which is now available for downloading on the P2 Framework Web site at http://www.epa.gov/oppt/p2frame- 
work. The manual describes each of the models, explains how they are used to estimate toxicity and risk, and includes several case studies showing how the model results are used to predict potential risk.

\section{Project XL Initiatives from Two P2 Framework Partners}

Not long after OPPT released the P2 Framework, EPA launched Project $\mathrm{XL}$, an initiative aimed at improving approaches to pollution prevention. Project XL (standing for eXcellence and Leadership) was open to anyone-including chemical companies, utilities, and manufacturing facilities-in all business sectors. Information on Project XL is available at http://www.epa.gov/ projectxl/.

Project XL invited stakeholders to suggest innovative new ways to prevent or reduce pollution. Companies interested in participating submitted proposals to EPA describing their ideas. If the proposal was accepted, the participant could qualify for regulatory relief.

Two companies who were partnering with OPPT to learn how to use the P2 Framework models, Eastman Kodak and PPG Industries, submitted Project XL proposals based on using the models to screen chemicals at the research and development stage.

\section{Kodak Documents Economic and Business Benefits from Using the P2 Framework}

As documented in Kodak's Project XL proposal, the company incorporated the P2 Framework into their research and development process. Kodak shared their experience using the P2 Framework with others in the industry through publications and presentations at conferences and meetings. They also conducted a cost accounting study to describe the economic and business benefits of applying risk screening in research and development.
The cost accounting study was conducted by the Tellus Institute, who worked with Kodak to compare and document new chemical product development at Kodak both before and after incorporating the P2 Framework models.

The Tellus Institute Kodak case study ${ }^{1}$ documented how the P2 Framework screening models gave Kodak a competitive advantage and helped them increase profits. The case study held a powerful message that all business managers would readily understand: Prescreening chemicals for toxicity and risk potential at the research and development stage improves the bottom line.

\section{PPG Industries Validates Aquatic Toxicity SARs in the P2 Framework}

PPG Industries, a major manufacturer of paints, coatings, glass, and fine chemicals, also submitted a Project XL proposal based on use of the P2 Framework. Like Kodak, PPG planned to incorporate the P2 Framework into their product development efforts and share their experience using the Framework. In addi-

\section{Project XL invited stakeholders to suggest innovative new ways to prevent or reduce pollution.}

an independent validation of ECOSAR.

PPG had previously submitted several dozen chemicals to both OPPT and Environment Canada, which requires the submission of test data with new chemical notifications. PPG compared the aquatic toxicity test data submitted to Canada against the ECOSAR predictions for these chemicals. They concluded that ECOSAR SARs were 87 to 90 percent accurate when compared to test data. ${ }^{2}$

\section{Regulatory Relief Was a Secondary Benefit}

Kodak and PPG were eligible for regulatory relief under Project XL. Both companies asked that 
the usual 90-day review period be shortened to 45 days for submissions developed using the P2 Framework models under their Project XL proposals. EPA agreed, and allowed Kodak and PPG to submit a Project XL chemical as both a PMN and a TME (Test Market Exemption), something not ordinarily allowed under TSCA.

The benefit of the simultaneous submissions was that when the prescreened low-toxicity/lowrisk chemical was dropped from review at day 45 , the company could begin manufacture immediately, as was customary for a TME, instead of having to wait until the conclusion of the usual 90day PMN period.

\section{The chemicals of greatest concern are toxics that persist in the environment and bioconcentrate in living organisms.}

Both XL projects ran for three years. It was very interesting to note that PPG took advantage of the expedited review only rarely, and Kodak never used the regulatory relief. Kodak stated that the option for regulatory relief was appealing. However, the most significant benefits they gained came from reduced product development costs, decreased waste generation, reduced regulatory liability, and the capacity to deliver products to the customer on schedule.

\section{The PBT Profiler: The P2 Framework's Next Generation}

In the process of working with industry and helping them learn to use the P2 Framework models, OPPT learned that many companies (especially small companies) cannot afford to hire chemists/toxicologists and get them trained in the proper use of screening models.

Partly in response to this, OPPT developed the PBT Profiler from components of the P2 Framework. The Profiler represents an effort to develop a model that will be widely available to industry, easy to use and interpret, and helpful in identifying potentially persistent, bioaccumulative, and toxic chemicals.

There is general agreement that the chemicals of greatest concern are toxics that persist in the environment and bioconcentrate in living organisms. Chemicals that have all three of these properties are known as PBTs. They include DDT, PCBs, and dioxin. PBTs are responsible for some of the worst environmental contamination in communities like Times Beach and Love Canal.

\section{Using the PBT Profiler}

The PBT Profiler evaluates a chemical's structure for potential PBT properties. Users can access the model at no charge at http://www.pbtprofiler.net. By entering a chemical's CAS Registry Number, they can obtain:

- information on the chemical's potential PBT characteristics;

- a comparison of the Profiler's predictions against the EPA New Chemical Program criteria for persistence, bioaccumulation, and toxicity;

- information on environmental fate; and

- information on "P2 considerations" to assist in risk management of the chemical.

\section{Input from Industry}

Extensive effort was invested in development of the PBT Profiler model. One factor contributing to its acceptance and wide use is that the principal users (specifically, members of the chemical industry) worked with EPA very early in the development process.

The American Chemistry Council, the Synthetic Organic Chemical Manufacturers Association, and leading chemical manufacturers, with assistance from Environmental Defense, 
collaborated with EPA in developing the PBT Profiler.

\section{Sustainable Futures: EPA Scales Up the Successful P2 Framework XL Projects}

The Agency was very pleased with the results of the Kodak and PPG Project XL initiatives. As a result, the Agency decided to "scale up" the concepts and offer the program nationally so that any company that prescreened new chemical submissions could get regulatory relief.

On December 11, 2002, OPPT announced the Sustainable Futures Pilot Project in a Federal Register notice, which is available at http:// www.epa.gov/fedrgstr/EPA-TOX/2002/December/ Day-11/t31243.pdf. "Sustainable Futures" is the name that has been given to the programmatic structure developed by OPPT to make the benefits of using the P2 Framework risk-screening methods available nationwide.

\section{Benefits of Sustainable Futures}

Under Sustainable Futures, OPPT is offering the same form of regulatory relief to qualifying participants that was offered to Kodak and PPG under their Project XL agreements-that is, submission of the chemical substance as both a PMN and a TME. By submitting a low-toxicity/low-risk chemical under Sustainable Futures, the company can potentially go to manufacture at 45 days instead of 90 , thus cutting the review time in half.

The Sustainable Futures Pilot Project offers participating companies:

- access to the P2 Framework and PBT Profiler models;

- hands-on training with Agency experts;

- one-on-one detailed technical assistance;

- regulatory relief for qualifying new chemicals (as described above); and

- a small business assistance program.

\section{Qualifying for Regulatory Relief Under Sustainable Futures}

In order to qualify for regulatory relief in the form of expedited PMN review, Sustainable Futures participants must demonstrate their competence in using the P2 Framework. In order to do this, companies need to:

- take the necessary training;

- apply the P2 Framework and demonstrate to EPA that this information helped guide decision-making regarding their PMN submission; and

- submit five to ten successful (i.e., not regulated by EPA) PMNs that they developed using the P2 Framework.

OPPT will continue to independ-

By prescreening chemicals, companies can identify problematic substances and search for safer alternatives.

ently evaluate each Sustainable Futures PMN submitted.

\section{Working Collaboratively with Business}

Sustainable Futures is an effective forum for the Agency and industry to work collaboratively toward the shared goals of pollution prevention, risk reduction, environmental stewardship, and sustainability.

Companies can gain significant benefits from prescreening new industrial chemicals using the same models that EPA will use to review the same chemical. Doing so allows users to identify potential chemical toxicity, exposure issues, and ultimate risk problems even before the chemical is synthesized.

By prescreening chemicals, companies can identify problematic substances and search for safer alternatives. If no substitute can be found for a specific chemical, the company will have an 
"early warning" about the risk concerns that need to be mitigated. Including mitigation information in the PMN submission can greatly speed time to market.

\section{Lessons Learned from Working with Industry}

\section{Business Benefits of Prescreening Chemicals}

In the process of working cooperatively with industry and helping them use the Agency's screening models, OPPT has learned that the greatest potential benefits to companies may not come from expedited review. Instead, participating companies state that they perceive the greatest benefits to be factors such as greater business cer-

Kodak found that prescreening chemicals at the R\&D stage provided greater business certainty. tainty, reduced product development costs, decreased waste generation, increased innovation, and enhanced profits.

All of these factors combine to give participating companies a competitive advantage over those that do not prescreen chemicals at the research and development stage. OPPT became aware of several of these potential benefits while working with Kodak and PPG on their Project XL initiatives. Some key business benefits are highlighted briefly below.

\section{- Business Certainty}

Kodak found that prescreening chemicals at the $\mathrm{R} \& \mathrm{D}$ stage provided greater business certainty, as documented by the Tellus Institute in its previously described case study.

Using the P2 Framework to prescreen PMNs allowed Kodak to predict the concerns the Agency might have when the PMN was finally submitted for review. This decreased regulatory uncertainty and allowed Kodak to more confi- dently estimate when production of the chemical could begin. Kodak could now tell a client more precisely when they could deliver the new chemical. This represented a significant business advantage over their competitors.

\section{- Reduction in Product Development Costs}

This benefit was also documented by the Tellus Institute report on Kodak's experience. Being able to determine whether a particular chemical might create concerns greatly reduced the costs required to identify successful candidate chemicals and processes and bring new chemical products to market.

\section{- Increased Innovation}

Using chemical risk prescreening models facilitates increased innovation because it allows the submitting company to consider many more chemical alternatives. This increases their chances of identifying a chemical with better performance characteristics, or one that is more environmentally preferable, in addition to decreasing the probability of regulation.

\section{- Increased Profit}

The factors described above can all contribute to increased profits for companies that use chemical risk prescreening models. In addition, these companies' profits can be enhanced further through the intangible (but invaluable) positive public relations benefits they realize by prescreening chemical alternatives at the research and development stage.

\section{- Competitive Advantage}

Overall competitive advantage is the major benefit that is being realized by forward-thinking companies that are incorporating product stewardship methods (including prescreening of chemicals using the P2 Framework methods) into their operations. 


\section{Some Technologies Were Not as Transferable as Hoped}

The Agency is learning many additional valuable lessons during the outreach efforts to industry that have culminated in the Sustainable Futures Pilot Project. One major lesson is that these methods have sometimes not been as transferable as OPPT had hoped.

An example is the critical step of selecting a close analogue for a chemical that lacks data. Accurately selecting a close analogue requires many years of experience in chemistry and toxicology. OPPT has highly skilled and experienced scientists who have focused their careers on reviewing toxicity studies and data, and gaining a sufficient knowledge of toxic modes to be able to predict how a chemical structure will control the ultimate toxicity of that chemical.

Toxicologists with chemical companies often have many functions, and cannot focus on becoming expert in selecting analogues. OPPT is exploring methods of capturing the hard-earned, valuable expertise of its toxicologists and making this available to industry.

\section{Models Are Applicable to Both New and Existing Chemicals}

The chemical risk-screening models that OPPT developed to screen new chemicals submitted under TSCA are also being applied to existing chemicals. As discussed previously, most existing chemicals in commerce lack the publicly available data needed to adequately assess their risk.

Now the OPPT screening models that have become the focus of Sustainable Futures are being used to screen groups of existing chemicals as well. This allows the model users to identify existing chemicals that may pose concerns. It also allows users to prioritize those chemicals that should be evaluated first, or in greatest detail.
This is especially true of the PBT Profiler. Major chemical companies, including SC Johnson and Bayer, are using the PBT Profiler to screen many chemicals in order to pinpoint those that may have concerns, or to identify the most environmentally preferable chemical alternative.

Like all screening models, the P2 Framework and PBT Profiler have conservative defaults. They are best used to prioritize chemicals and identify potentially problematic chemicals for more detailed evaluation.

\section{Conclusion: A Win-Win-Win Outcome for Industry, EPA, and the Environment}

The Sustainable Futures Pilot Project has been a rewarding outreach effort. It has successfully demonstrated that cooperative efforts can result in the greatest benefits for everyone involved. This is truly a "win-win-win" situation.

The chemical industry wins by increasing profits and gaining competitive advantage.

EPA wins by advancing its pollution prevention and risk reduction goals.

Most importantly, the environment wins because safer chemicals and processes are entering commerce.

\section{For More Information}

Additional information on Sustainable Futures is available at http://www.epa.gov/opptintr/ newchems/sustainablefutures.htm.

\section{Notes}

1. Votta, T. J., \& White, A. L. (1999). Design for competitive advantage: The business benefits of the EPA pollution prevention assessment framework in new product development. Boston: The Tellus Institute.

2. Chun, J. S., Nabholz, J. V., \& Wilson, M. J. (2000). Comparison of aquatic toxicity experimental data with EPA/OPPT/SAR prediction on PPG polymers. Pittsburgh, PA, and Washington, DC: PPG Industries and EPA Office of Prevention, Pesticides and Toxic Substances. 
Maggie Wilson is a biologist with the Risk Assessment Division of EPA's Office of Pollution Prevention and Toxics. She has a master's degree in environmental science and public policy. Before joining OPPT, Ms. Wilson worked for the Fairfax County (Virginia) Park Authority as a naturalist, and at the Smithsonian developing a research database to contain information on fossil sites. She also helped produce the Federal Highway Administration's guidance document Roadside Use of Native Plants. She later joined an environmental consulting firm, where she conducted a series of studies for EPA's Office of Research and Development using biota to assess environmental impacts to Superfund sites, and conducted training workshops for EPA's Regional Biological Technical Assistance Groups, providing support to Superfund site managers. She also provided support to EPA in screening new chemicals under TSCA using the exposure models E-FAST and ReachScan. She joined EPA in 1998 and continued her work on the P2 Framework outreach efforts, assessing aquatic toxicity of new chemicals under TSCA, and helped develop the PBT Profiler and Sustainable Futures. Ms. Wilson chaired an OECD Issue Team, Tools for R\&D Screening, that collected information on chemical risk-screening models used by member countries, developed an OECD Web site that contains a searchable database of risk-screening models, and conducted a pilot describing the steps needed to validate QSAR models. 